Journal of Animal and Veterinary Advances 18 (7): 227-238, 2019

ISSN: $1680-5593$

(C) Medwell Journals, 2019

\title{
Types of Animal Diseases and Their Potential Threats to Sustainability of Animal Biodiversity
}

\author{
Aweke Engdawork \\ Department of Veterinary Medicine, Researcher at Ethiopian Biodiversity Institute, Ethiopia
}

\begin{abstract}
Animal genetic resource diversity ensures the continuity of biodiversity and their survival as adaptation to several challenges and agro-ecologies. Animal biodiversity has valuable contribution in animal products variety and to their ecological balance. Currently, animals and their genetic diversity are being under several threats, challenging their sustainability and survival. Infectious diseases are emerged as a potential threat to several animal species and breeds, particularly challenging endangered or at risk animal species/breeds. There are many animal diseases which are contagious, virulent and epizootics inducing dramatic mortality and morbidity in both domestic and wild animal population. Invasive infectious diseases are spreading to susceptible populations unaffected before including to species already being threatened by other factors. Emerged infectious diseases are already been involved in the extinction of some species while threatening exist in most of animal species. Generally, animal epizootics affect about $5 \%$ of globally threatened birds (67 species) and 26 species ( $3 \%$ ) of threatened mammals are impacted by infectious disease. However, huge impact is observed in amphibians that are particularly affected by disease with $17 \%$ ( 317 species). Different animal diseases possess a significant threat and can wipe out most or entire susceptible animal breed/species or multi-species. Rinderpest, Anthrax, African horse sickness, Avian influenza, Newcastle disease, Rabies, Canine distemper, chytridiomycosis, etc., all these can highly threat susceptible animal species/breed. Rinderpest and rabies with canine distemper has threatened Ethiopian cattle population and the endangered Ethiopian wolf, respectively while anthrax outbreak caused threats in herbivores population's at Mago National Park. Infectious diseases are one of the constraints in the survival and conservation effort of animal genetic resource diversity. Therefore, organized diseases surveillance and control strategies should be employed to safeguard the sustainability of animal biodiversity. Furthermore, advanced studies are required to clarify current distribution and intensity of diseases impact on global animal biodiversity.
\end{abstract}

Key words: Animal, biodiversity, infectious diseases, sustainability, threats, animal

\section{INTRODUCTION}

The need for animal genetic resource is definitely certain for human's contented livelihood by providing a range of animal products and services (Givens, 2010). Animal originated food products are an important source of variable nutrients that provide the necessary supplement and diversity to staple plant-based diets (Murphey and Allen, 2003; Rands et al., 2010). However, the necessity of keeping livestock and maintain their genetic resource go far beyond food source, in providing energy, fiber and wool, skin and hide, draught power and serving as tangible assets and icon of social value. Their contributions in supporting livelihoods, especially of the developing countries are a key feature of livestock and animal genetic diversity (FAO., 2010).

Animal genetic resource diversity is being exhausted by a range factors throughout the world. Threats to Animal Genetic Resources (AnGR) include a wide variety of factors, ranges from threatening a particular animal breed to endangering and extinctions animal at species level. Inappropriate approaches to animal biodiversity on a local scale to major national/international economic, social and environmental aspects pose a danger to sustainability of AnGR. Animal breeds and/or species vary in vulnerability to particular threats (Gibson et al., 2006; FAO, 2007). Animals had attachment and adaptation to their ecology and production environments. Translocation of AnGR around the world is difficult in terms of transportation and establishing and survival of animal populations in the new locations. Global animal biodiversity is being flourished through influential threatening factors including habitat destruction, over exploitation, climate change, cross breeding/hybridization and diseases (FAO, 2009; Alemayehu, 2013).

Animal diseases are the major health and welfare concerns of both domestic and wild animals. Infectious diseases, especially, virulent and contagious diseases agents are generally regarded as a threat in causing of decline or fluctuation in animal populations. However, diseases may not be the primary factor in causing the actual endangerment or extinction of the species (MacPhee and Greenwood, 2013). Based on the assessment of critically endangered species apparently 
threatened by infectious disease listed by the International Union for Conservation of Nature (IUCN, 2004; Baillie et al., 2004), in majority of cases there were corresponding factors to support infectious disease as a threat for the animal population (Smith et al., 2006).

Emerging Infectious Diseases (EID) driven threat in animal population are observed in a wide array of invertebrate and vertebrate taxa indicating a global phenomenon (Breed et al., 2009). Death rates in the range of $50-75 \%$ or above is extremely high that can cause enormous lethality and animal population decline and endangerment. Ebola, rinderpest, avian flu, chytridiomycosis infections, etc., have caused huge population losses in the world (Weingartl et al., 2012). High percentages of animal lose have also been recorded in other diseases outbreaks among susceptible animal populations observed in different times and parts of the world (Scott, 2000).

Diseases epizootics possess influential features as a disaster and emergency in threatening animal genetic diversity. Outbreaks have the capacity to kill huge number of animals in the population in a short period of time. Diseases are a potential threat to animal species/breed populations that are concentrated within a limited geographical area or with only small population size. Animal genetic resource threatened due to disease epizootics where that large numbers of animals potentially a large proportion of a given animal population could be die, either directly because of the severity of the disease or because of the implemented programs to control and eradicate the disease (Bishop and Woolliams, 2004).

Serious diseases affecting a large number of animals and spreading across a wide geographical area pose a greater threat to animal genetic resource. For the particular animal species/breed that is threatened or an at-risk breed category, the death of a thousand, a few hundred or even a few tens of animals can be devastating. Foot and mouth disease epizootic of 2001 in United Kingdom or avian influenza outbreaks that struck parts of Southeast Asia in 2003/2004 resulted in large scale lose in terms of livestock deaths and their economic consequences (FAO, 2012). Disease epizootics have continued to inflict an enormous threat on the animal genetic resource (domestic animal and wildlife's) and loss of biodiversity, especially if the diseases are introduced to the native animal populations (Hochachka and Dhondt, 2000).

Dissemination of infectious diseases and parasites and the emergence of new diseases are expected to continue evolving, influenced by high animal population, international trade, globalization and climate change. These driven opportunities may leads to thriving period of emerging infectious disease (Bouley et al., 2014). Climate change has the potential to affect all the components of disease systems (pathogens, hosts, vectors and environment), may increase the survival of pathogens and vectors and creating conducive situation for their reproduction or may increase the vulnerability of animal population. Threats of emerging diseases, parasites and their spread into new areas are potentially aggravated by antigenic drift/shift and the spread of antibiotic resistance and resistance to anthelmintic used against the control of parasites and disease vectors (Mackey et al., 2014).

Ethiopia is a home of several varieties of faunal species and diseases are loosely controlled where disease intervention consists of mass inoculations following outbreaks rather than preventive measures. The country is known for it's major livestock resource in Africa and rich in considerable wild animals both in terms of number and diversity (Lemma, 2012). Even if, the biggest threat to wildlife is loss of habitat often triggered by the growth of farmland and uncontrolled grazing, diseases are still can seriously threaten wildlife populations with severe decline and extinction. Currently, about one-third of animal genetic resources are being at high risk of endangerment and extinction throughout the world attributed to several disasters and emergencies (FAO, 2010): Therefore, the objectives of this review paper are:

- To give an overview on the types of animal diseases

- To show the potential impacts/threat of diseases epizootics on the diversity of animal genetic resource

- $\quad$ To deals with methods and strategies for minimizing and controlling diseases impacts on animal biodiversity

\section{MATERIALS AND METHODS}

Types of animal diseases and their scale of occurrence: There are different types of animal diseases with a number of classifications, causing mild to severe debilitating epizootics in susceptible animal populations. Animal mismanagement and uncontrolled translocation resulted in the spread of diseases which adversely affect animal production throughout the world. Currently, numerous animal diseases worried in threating endangered animal species and breeds and their zoonotic importance with severity to the public (BoA., 1999; Springbett et al., 2003). Wild animals play a major role in disease reservoir and transmission and so they are important when addressing certain diseases in domestic animals or humans. There are also many types of diseases harbored by domestic animals which cause trashes in wild animals. Different animal diseases are important for biodiversity in their own right with impacts including native species declines and animal welfare which have received less attention globally (Baillie et al., 2004). Most commonly diseases are categorized by their causative agent in to infectious diseases and non infectious diseases, where both categories contain several diseases affecting 
every animal species. However, diseases could be classified based on different methods (Hubalek and Rudolf, 2010), some of them are the following:

- Diseases classification based on their causative agent

- Diseases classification based on their source of infection

- Diseases classification based on the type of host species infected

- Diseases classification based on the system they affects

Infectious animal diseases: Infectious animal diseases are infections/illness caused by a certain pathogenic microorganisms and parasites. Many pathogenic organisms live in/on animal's body and their environment (Bengis et al., 2002). Many of them are normally harmless or even may helpful but there are also a number of organisms and parasites causing latent to serious contagious disease. Animals are exposed directly or indirectly to infectious organisms in many ways including breath, urine or manure of other animals and from arthropods (Turton, 2000).

Infectious agents enter the individual through the skin, mucous membranes, lungs, mouth or reproductive tract. Agents such as germs (bacteria, viruses, fungi, rickettsia) and parasites (worms, protozoa, arthropods), infect or infest various tissues and organs of animals. The germs and protozoa invade and multiply inside or outside of tissue while helminthes and arthropods invade and develop in the lumen of hollow organs and between cells of tissues. Tissue damage results from increased pressure, adverse reactions, toxins or feeding by the disease agents (Kahn and Line, 2010). Infectious disease agents (Hubalek and Rudolf, 2010) include:

- Bacteria (anthrax, brucellosis, haemorrhagic septicemia, black leg, tuberculosis, leptospirosis, camphyllobacteriosis, tetanus, listeriosis, etc.)

- Rickettsia (anaplasmosis, ehrlichiosis, Q fever, scrub typhus, e.g., Cowdriosis, East coast fever, etc.)

- Viruses (foot and mouth diseases, rinderpest, avian flu, rabies, canine distemper, ebola, PPR, Newcastle disease, etc.)

- Fungi (aspergillosis, histoplasmosis, coccidioidomycosis, dermatophytosis, cryptococcosis, epizootic lymphangitis, mycosis, etc.)

- Helminthes (lungworm, liver flukes, stomath worms, schistosomiasis, strongyloidiasis, trichinosis, trichuriasis etc.)

- Protozoa (trichomoniasis, trypanosomiasis, toxoplasmosis, coccidiosis, babesiosis, balantidiosi, amebiasis, etc.)
Noninfectious animal diseases: Noninfectious diseases are not caused by virulent pathogens and are not communicable from one animal to another, except may genetically. They may be caused by nutritional/metabolic factors or by the environment in which an animal lives. Noninfectious animal diseases (Engdawork, 2019; include:

- Metabolic/nutritional imbalance (milk fever, ketosis, pregnancy toxemia, fatty liver disease, mineral/vitamins deficiencies, etc.)

- Toxicities (lead poisoning, arsenic, bracken fern, lantana camara, strychnine poisoning, molybdenum poisoning, etc.)

- Genetic diseases (hereditary epilepsy, congenital heart anomalies, dwarfism, osteopetrosis, etc.)

- Neoplastic diseases (transmissible venereal tumor, osteosarcoma, leukemia, lymphadenopathy, adenocarcinoma, etc.)

Metabolic diseases usually result from a disturbance in the normal balance of the physiological mechanisms that maintain stability or animal homeostasis. Pregnant animals must adjust metabolically to the dramatic increase in energy and nutrient requirements needed to ensure milk production in the ensuing lactation. Production diseases are those induced by improper management practices where high producing dairy cow, ewe, mares fail in to metabolic imbalances (Gregory, 2019). Major physiological, nutritional, metabolic and immunological changes occur within periparturient period as the production cycle of the animal shifts from a gestational non-lactating state to the onset of copious milk synthesis and secretion (Sordillo and Raphael, 2013).

Poisoning by toxic chemicals such as toxic plants and heavy metals can cause serious diseases in every animal species including human beings. Some toxins are a potent toxins affecting the central nerves system, enterotoxins or causing musculoskeletal spasm. Many toxic chemicals are cosmopolitans, persisting in the environment. They destabilize ecosystems because of their bioaccumulation in organisms and toxic effects on animals and even death in most cases (Diaz, 2011). Cancer is an abnormal and uncontrolled growth of cells or tissues in the body which could be benign (restricted) or malignant (metastatic). Exposure to certain chemicals, viruses, ionizing radiations and complex hereditary factors are commonly regarded as the potential causative factors. Neoplastic diseases occurred in most animal species with extent of severity including dramatic lethality (Joshi and Jadon, 2012; Modiano, 2012).

Scale of diseases occurrence: The occurrence and spread of diseases in animal population vary depending on environmental conditions, immunological status of the population, population density, availability of vectors and 
reservoirs, nature of the pathogen and its survival in the environment. There are different scales in the spread and occurrence of animal disease.

Sporadic: Disease that infrequently occur in some individuals of a population (malignant catarrhal fever, paratuberclosis, etc.).

Enzootic: Disease that usually present in a particular locality but with lower prevalence (pneumonic pasteurollosis, etc.).

Epizootic: Disease that affects a large number of animals in a short period of time in a particular area occurrence of above expected levels (foot and mouth disease, PPR, etc.).

Panzootic: Disease that spreads rapidly over a very large area and effects many animals in a short period of time (Avian influenza etc.).

\section{RESULTS AND DISCUSSION}

Diseases impacts on animal biodiversity: Diseases epizootics can cause chronic population declines, dramatic sweep of entire population or progressive influence in the reproductive success and survival of animal breed/species. Invasive diseases now appear to be spreading to populations previously unaffected including to species already seriously threatened by other factors. Infectious diseases have already been implicated in the extinction of some species. Overall, diseases (both native and invasive) affect some $5 \%$ of globally threatened birds (67 species). For threatened mammals, only 26 species (3\%) are impacted by disease. However, it is the amphibians that are particularly affected by disease with $17 \%$ (317 species) of threatened species potentially impacted (IUCN, 2004; Pounds et al., 1997).

EID influences the conservation effort of animal genetic resource diversity and are one of the constraints in their survival. Outbreaks of infectious diseases frequently devastate single or multiple animal species/breed population (Perry et al., 2002). There are several animal species already under threat for various reasons being severely impacted by infectious diseases as shown in Table 1. Anthropoids, particularly in Africa have been threatened by Ebola and Marburg hemorrhagic diseases (Leroy et al., 2004). Canine distemper caused devastating outbreak in black-footed ferrets and lions (Roelke-Parker et al., 1996; Williams et al., 1988) while transmissible facial tumour disease endangered Tasmanian devils (Pearse and Swift, 2006). Amphibian species was linked to an emerging, highly pathogenic disease that looked at the pattern of disappearances of 14 species of frogs endemic to Australia's east coast (Laurance et al., 1996). The chytrid fungal disease caused by Batrachochytrium dendrobatidis was identified as the agent resulting in amphibian dramatic loss (Berger et al., 1998; Longcore et al., 1999). Amphibians are under global assault from a large variety of impactors additional to infectious diseases. As many as 120 amphibian species have already been driven to extinction in recent decades (Smith et al., 2006; Schloegel et al., 2009).

A snail called Partula turgida, from French polynesia that succumbed to an infection of the microsporidian Steinhausia species (Cunningham and Daszak, 1998), thereby reducing reproductive survival of the species. Invertebrate's extinction and endangerment by disease also goes to the loss of the eelgrass limpet (Lottia alveus) (Orth et al., 2006). Eelgrass wasting disease killed off sea grasses on both sides of the Atlantic on such a massive scale that all known populations of this limpet terminally crashed (Carlton et al., 1991).

There are a number of mammalian and bird species surrendering to different infectious diseases (MacPhee, 1997). Different canid's species became exceedingly threatened with distemper and associated outbreaks, observed thylacines and Australian marsupials. Disease played a role in the final disappearance of thylacines (De Castro Castro and Bolker, 2005). Many bird extinctions and extirpations are linked to the serious threat of infectious diseases (Table 1). Panzootic caused by the inadvertent introduction of Culex quinquefasciatus, a vector of avian malaria (Plasmodium relictum) trashes endemics Hawaiian honeycreepers in the Hawaiian Islands (Smith et al., 2006). Avian pox (Poxvirus avium) limits the distribution and abundance of susceptible bird species that primarily govern local or complete extinction (Warner, 1968).

More recently, the impacts of infectious disease on extant natural populations have been analyzed (De Castro and Bolker, 2005), indicates that infectious diseases as a significant cause of species endangerment. The mammalian species Koalas are under siege by two major pathogens, Kola retrovirus which causes substantial mortality (Hanger et al., 2000) and infectious Chlamydia pecorum, where serious overlapping infections leads to the local extirpation (Tarlinton et al., 2005). A cryophilous fungus (Geomyces destructans), cause massive mortality (white nose syndrome) in the Myotis Bat, where current mortality rates of the little brown bat may eventually suffer complete regional extinction (Frick et al., 2010). The neoplastic disease, facial tumor disease, a severe threat to the Tasmanian devil (Sarcophilus harrisii) is currently receiving a great deal of attention because of its highly unusual nature (Murchison et al., 2012). 
J. Anim. Vet. Adv., 18 (7): 227-238, 2019

Table 1: Infectious animal diseases serious threats on different species of animals, which have been observed globally (Daszak et al., 2000)

\begin{tabular}{|c|c|c|c|}
\hline Disease & Pathogen & Animal Hosts & Impact on the Species \\
\hline Canine distemper & Canine distemper/morbilli virus & Canids & $\begin{array}{l}\text { Extinction of African wild dog and black-footed ferret; } \\
\text { Threat to Ethiopian wolf }\end{array}$ \\
\hline $\begin{array}{l}\text { Amphibian } \\
\text { chytridiomycosis }\end{array}$ & $\begin{array}{l}\text { Batrachochytrium } \\
\text { Dendrobatidis }\end{array}$ & Range of amphibians & $\begin{array}{l}\text { Mass mortalities and population declines; local and } \\
\text { possibly global extinctions }\end{array}$ \\
\hline Steinhausiosis & $\begin{array}{l}\text { Steinhausia species } \\
\text { (protozoan parasite) }\end{array}$ & Partula snails & Global extinction of Partula turgida \\
\hline Avian malaria & $\begin{array}{l}\text { Plasmodium species } \\
\text { (protozoan parasites) }\end{array}$ & Birds & High mortality in susceptible species, e.g., penguins \\
\hline White nose syndrome & Fungus (Geomyces destructans) & Myotis bats & $\begin{array}{l}\text { Massive mortality eventually suffer complete regional } \\
\text { extinction }\end{array}$ \\
\hline $\begin{array}{l}\text { Ebola and Marburg } \\
\text { hemorrhagic fever }\end{array}$ & $\begin{array}{l}\text { Marburg and Ebola virus } \\
\text { (filoviruses) }\end{array}$ & Nonhuman primates, & High mortality in captive and wild nonhuman primates \\
\hline Varroasis & Varroa jacobsoni (mite) & Honeybees & $\begin{array}{l}\text { Catastrophic mass mortality, e.g., } 75 \% \text { loss of feral } \\
\text { colonies }\end{array}$ \\
\hline Crayfish plague & Aphanomyces astaci (fungus) & Crayfish & $\begin{array}{l}\text { High mortality rates with population declines, } \\
\text { threatening native species with extinction }\end{array}$ \\
\hline
\end{tabular}

Diseases capable of threatening biodiversity: There are different animal diseases which can pose a significant threat to animal genetic diversity. The threat may ranges from threatening a particular animal breed to endangering animal at species level. Diseases epizootics may wipe out most or entire susceptible animal population. A large number of EID have recently appeared and threatening animals, particularly species at risk of extinctions around the world (Daszak et al., 2000; Jones et al., 2008). Most pathogens can infect different species and these generalist pathogens pose the greatest threat to disease mediated extinction. Because high prevalence in alternate hosts, coupled with cross species transmission, can increase the likelihood of disease persistence and host extinction (Pedersen et al., 2007). There are many exemplary diseases which can pose great threat to animal biodiversity.

Anthrax: Anthrax is best known for its use as a weapon of bioterrorism. It mostly affects herbivores but also including some carnivores and primates. It causes per-acute/acute disease where mortality rate is very high (>95\%) particularly in herbivores. A massive outbreak of anthrax in the wildlife of the Malilangwe Wildlife Reserve in Zimbabwe at 2004 resulted in the death of almost all the reserve's estimated 500 Kudu (Tragelaphus strepsiceros). Other species badly affected were Nyala (Tragelaphus angasi) and Bushbuck (Tragelaphus scriptus) which suffered losses of approximately 68,48 , $44 \%$ of their populations, respectively. Buffalo (Syncerus caffer) were also badly affected and although their population suffered only a $6 \%$ loss, the numbers of deaths ranked second highest after kudu (Clegg et al., 2007).

During the late 19th and early 20th century, anthrax was among the foremost causes of uncontrolled livestock mortality in the world. Numerous devastating anthrax outbreaks have also been reported in livestock including cattle, goats and sheep in Tanzania at the eastern part of Serengeti National Park with $<500$ deaths. Importantly around 153 hippopotamus also died in Kilombero river due to anthrax outbreak in the early 2016 (Lembo et al., 2011). During 20th century, when anthrax outbreak reaches at its peak in South Africa, it has caused a devastating mortality with estimated death of 30,000-60,000 animals within in a year (Hugh-Jones and De-Vos, 2002).

Canine distemper: Canine distemper is highly infectious for many species of carnivores and causes high death rates in immunologically naive populations. A domestic dog virus is wiping out wild carnivores around the world. As domestic dog populations increase, the disease is spreading to newer areas and jumping to a wider range of carnivores (Harder et al., 1996). The most intensively studied CDV outbreak has been in black-footed ferrets, African wild dog (highly endangered carnivore) and the African lions in Serengeti National Park, Tanzania. In 1985, canine distemper slashed numbers of black-footed ferrets in Wyoming. While, in the early 1990's, CDV has killed many African wild dogs and wiped out about 1000 African lions and in late 2000, it killed 49 of 52 captive wild dogs in Tanzania within 2 months (Van de-Bildt et al., 2002).

Ebola: Many people think Ebola as a human disease but with good reason that recent outbreak killed about 10,000 people in West African countries. But it is originally the diseases of our closest relatives and has been wiping out populations of the great apes. The disease possesses a high mortality rate among susceptible species where the highest rate recorded among chimpanzees and gorillas. Ebola outbreaks in the Republic of the Congo killed about 5000 critically endangered western gorillas between 2002 and 2003 at the Lossi Sanctuary. In late 2001 and early 2002, human outbreaks of Ebola had flared up along the Gabon-Congo border (Leroy et al., 2004). Number of gorillas and chimpanzee carcasses were found in the different sites of the sanctuary within few 


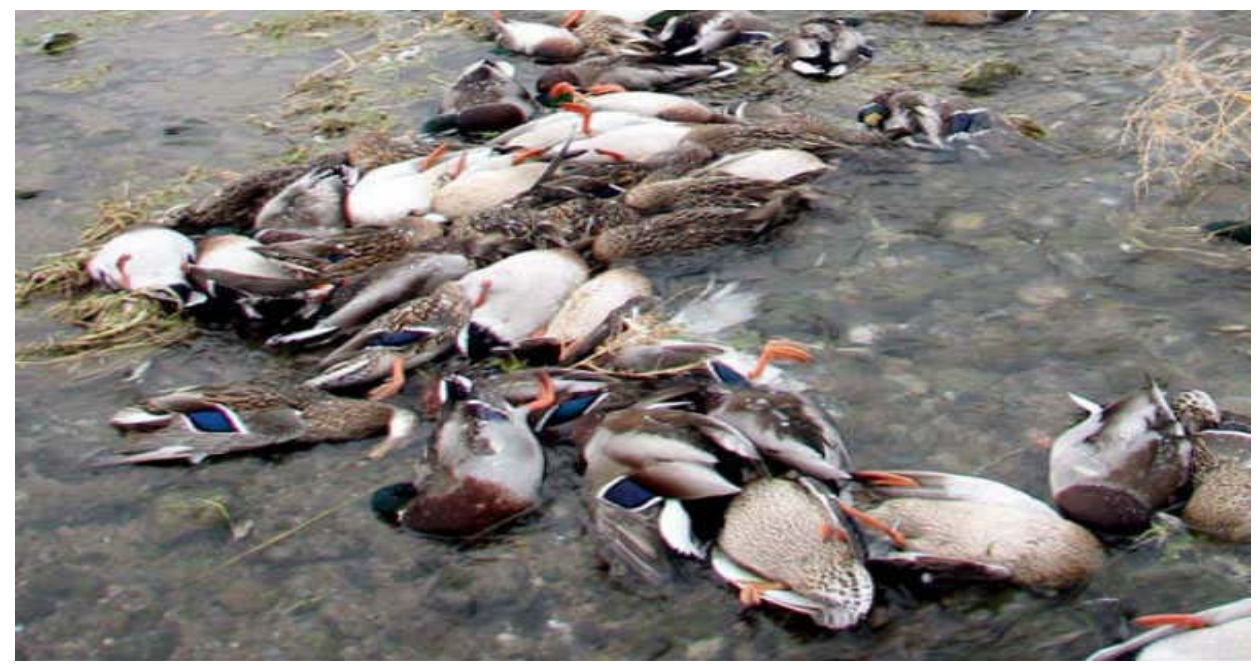

Fig. 1: Highly pathogenic avian influenza wiping out mass population of wild birds (Waterfowl) (DeLiberto and Keirn, 2016)

months at 2002 and by 2003, 91\% (130/143) of the individually known gorillas had disappeared (Rouquet et al., 2005).

Avian influenza: Highly Pathogenic Avian Influenza (HPAI), especially, the strain H5N1 is known for its worldwide distribution as was officially reported by all countries in 2004 (OIE., 2005; FAO., 2004). The most serious outbreak of avian flu appears widely in some Asian countries including Indonesia, Thailand and Viet Nam, with the latter two countries also reporting zoonotic impact (human cases and fatalities). The severity of this disease includes that the high levels of morbidity and mortality with flock mortality rates often above $50 \%$. The highly infectious nature of highly pathogenic avian influenza also requires several control methods to restrict an outbreak which would normally include the culling of apparently healthy birds that have been in contact with infected bird population (Rushton et al., 2004; FAO., 2005).

The presence of HPAI restricts international trade in live birds and poultry meat products and also affecting tourism. Infection of other poultry and livestock species with HPAI reported to infect ducks, geese, quails and pigs. Therefore, avian influenza infections is transmitted and maintained in multiple avian and mammal species with considerable morbidity and mortality in these species. Some avian species also serves as a reservoir of disease, especially in ducks and potentially creating influenza strains that threaten human health. Outbreak in Hong Kong's poultry population has killed the entire domestic poultry population while in Chine several thousands of Waterfowl have (Fig. 1) been dead (Leslie and Upton, 1999; DeLiberto and Keirn, 2016).
Chytridiomycosis: Chytridiomycosis is an emerging infectious disease of amphibians caused by an aquatic fungal pathogen, Batrachochytrium dendrobatidis (Bd) (Daszak et al., 2004). Amphibian die-offs in Australia indicating a chytrid fungal pathogen was devastating among susceptible frogs and other amphibian animals including some salamander species (Laurance et al., 1996). Batrachochytrium dendrobatidis appears to be specific to amphibians and is one of only two species of chytrid fungus known to parasitize vertebrates. The fungal (Bd) infection has been observed in numerous frog species, some salamander species and a single caecilian species (Typhlonectes species) in captivity (Raphael and Pramuk, 2007).

Batrachochytrium dendrobatidis may be responsible for the greatest disease caused loss of biodiversity in that it has caused the catastrophic decline or extinction of at least 200 species of frogs, even in pristine, remote habitats (Skerratt et al., 2007). These rapid, unexplained declines have occurred around the world while recently $\mathrm{Bd}$ has been implicated in the serious disappearances of Central American salamanders as well. When diseases have previously been associated with population declines and extinctions (Daszak et al., 2000), chytridiomycosis is the first emerging disease shown to cause the decline or extinction of hundreds of species not otherwise threatened. Currently over 350 amphibian species are known to have been infected by the disease.

Diseases threat to animal biodiversity in ethiopia: Ethiopia has long been recognized as a center of diversity for domestic animal genetic resource and wild faunal diversity which is vital component of agro-ecology. Loss of biodiversity is a worldwide concern where climate 
(a)

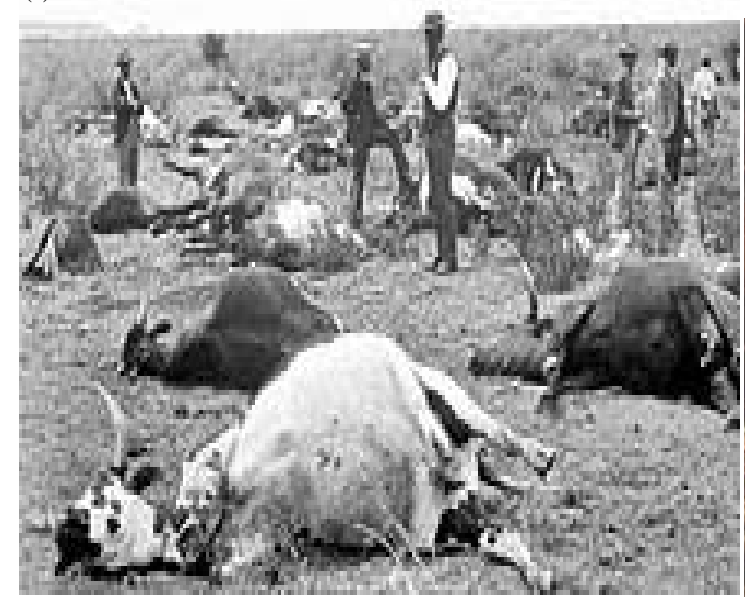

(b)

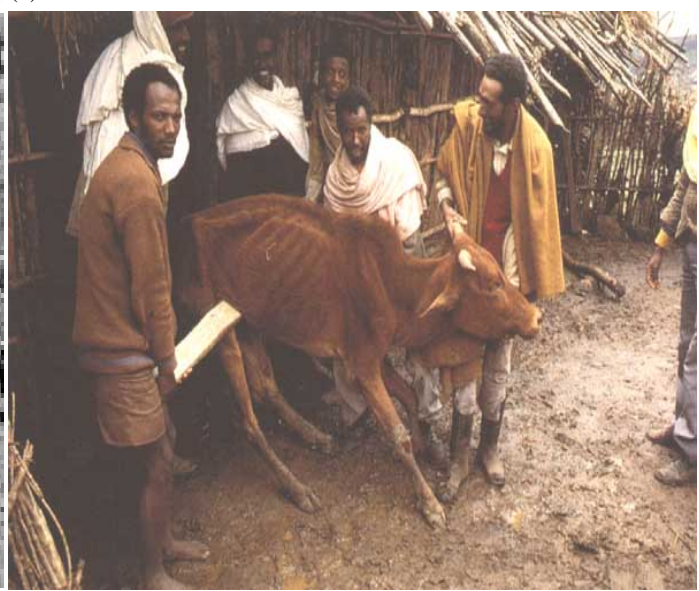

Fig. 2(a, b): Rinderpest outbreak causing dramatic mortality of cattle population in South Africa, (a) and rinderpest case in Ethiopia and (b) (Phoofolo, 1993)

change poses sensible fear and challenge to biodiversity conservation (Lemma, 2012). In Ethiopia, the primary cause is habitat destruction and fragmentation due to farmland expansion and grazing land demand to support livelihood of an increased population. The country's sustainable utilization and conservation of the animal genetic resources are very limited. Animal diseases along with other aggravating factors is cause of threats to maintenance of animal genetic diversity (IBC, 2009; Tilman et al., 2001).

Many animal diseases are highly prevalent in Ethiopia causing sporadic to devastating outbreaks. Even though the livestock sub sector contributes much to the national economy, its development is constraints by widespread animal diseases including viral, bacterial and parasitic infestation, poor veterinary service and accompanied by low diseases surveillance and control (Zewdie, 2004; MOA., 2012). Trypanosomosis is widely distributed in Ethiopia, particularly in the western and Southwestern lowlands and the major river valleys. It is a major problem to the utilization of large land resources (Getachew, 2005). Anthrax outbreak has also caused high herbivores death in Mago National Park, Southern Ethiopia (Shiferaw et al., 2002). Different diseases outbreaks faced the sustainability of domestic and wild animals in the country.

Rinderpest has threatened Ethiopian cattle: Rinderpest (cattle plague) is an acute, highly contagious viral disease of ruminants and was the most severe infectious disease of cattle characterized by its sudden development and high mortality. It is the most dreaded bovine plague that can destroy entire populations of cattle and buffalo. In regions that depend on cattle for meat, milk products and draft power, rinderpest has caused widespread famine and has inflicted serious economic and political damage. An epidemic in the 1890 's wiped out $80-90 \%$ of all cattle in sub-Saharan Africa (Fig. 2). Rinderpest is mainly spread by direct contact and by drinking water that has been infected by the dung of sick animals. It can also be transmitted in the breath and can infect wild animals and pigs as well as cattle (Scott and Gordon, 2000).

The cattle plague, known as rinderpest which in the 1700 's devastated Europe was introduced to Ethiopia. European countries lost most of their cattle throughout the 18 th century to rinderpest. The rinderpest which got a foothold through an Ethiopian seaport in 1887, decimated the cattle of northern Ethiopia and traveled to the rest of Ethiopia and the rest of Africa by 1897 (Scott, 2000; Zewde, 2002). At all events the rinderpest of 1888 which was very probably of a variety then little known in the country, appeared with unusual virulence and spread like wildfire soon affecting almost all parts of Ethiopia as well as much of the neighboring countries. The disease swept across the northern provinces of Tigray and Shewa southwards, resulting in an estimated $90 \%$ mortality of the country's cattle population and wildlife including buffaloes and antelopes (Pankhurst, 1985).

Rabies and CDV Threats on Ethiopian Wolf: Rabies is an infectious viral disease that is almost always fatal following the onset of clinical symptoms while Canine distemper virus (CDV; family Paramyxoviridae, genus Morbillivirus) constitutes one such threat and has caused outbreaks in a diverse range of canids (Alexander and Appel, 1994). Canine distemper virus is a major threat to the persistence of some threatened carnivore populations including the Ethiopian wolves. Serologic evidence for CDV within wolf populations has been reported (Laurenson et al., 1998), of 30 samples tested during 
1989-1992, a total of 9 (30\%) were seropositive for CDV. Rabies emerging as a particular threat to wild Canids, an outbreak has occurred in subpopulation of Ethiopian wolves in the Bale Mountains. Massive outbreaks of rabies and more recently, canine distemper have repeatedly decimated populations of Ethiopian wolves (Canis simensis) in the Bale Mountains of Ethiopia, where more than half of a global population of around 500 wolves live (Gordon et al., 2015). With up to 300 of the global estimate of 500 wolves, the Bale Mountains in south-central Ethiopia are home to the largest and most important population of this species (Marino, 2003). About 74 wolves were found dead during 2003/2004 where evidence indicates outbreak of rabies, overlapping or followed soon after by a canine distemper outbreak Rabies virus was diagnosed from 13 of 15 brain samples sent to the Centers for Disease Control and Prevention (CDC), USA (Kuzmin et al., 2003).

Diseases investigation and control: Disease investigation and control measures are often carried-out with the objectives of subsequent eradication of agents at the regional or country level. Diseases investigation is a systematic procedure in safeguarding the biodiversity to identify the source of infection with a view to control and prevent possible future occurrence. In most diseases investigations, the primary goal is control of the outbreak and prevention of additional cases (OIE, 2014). There need to improve understanding epidemiology of diseases to predict and respond the dynamics of disease to implement control measures. Epidemiology has create detailed association on disease conditions in animals that affect certain population, by which they are affected, the location of affected animals and the patterns of disease through time in the population (Abdo-Salem et al., 2006).

Prevention is the key in controlling animal diseases which is accompanied by precise diseases surveillance and extenuation strategies. Surveillance is always a component of a disease control programme and an updated assessment on the current animal health disease status is an essential and significant procedure (Stark and Salman, 2001). Appropriate diseases prevention and control measures should be developed to successfully combat the occurrence and expansion of outbreaks, and further eradication of any animal diseases (Geering et al., 1999). In general, diseases management constitutes 3 basic forms of strategies:

- Prevention of introduction of diseases in to certain population

- Control of existing disease through comparative measures

- Finally eradication

The major means to control infectious and contagious animal diseases include, preventive actions, arthropod vector control, host population control through selective culling, habitat management or reproductive control and vaccination (Gortazar et al., 2006). Management strategies should be applied to any one of or all components of the epidemiological triangle (the disease agent, host population and/or habitat/environment). Disease agents may be dealt with in the environment through disinfection or in the host through treatment. Host populations may be managed by immunization (vaccination and antisera transfer), by altering their distribution or density by genetic improvement or by extirpation and stamping out (Caron et al., 2013). Habitat modification may be used to reduce exposure to disease agents or to alter host distribution or density.

Environmental management constitutes, setting up of barriers or fences, a change in human activities and restricting translocation. Movement control, known as translocation control in wildlife is one of the most fundamental preventive actions in disease control for both domestic animals and wildlife (Smith et al., 2009). Quarantine remains a cornerstone in many animal disease control programs. A period of quarantine is usually a requirement for the importation of animals from another country, within a country or region for the control or eradication of specific infectious agents. Creating a barrier to disease movement has been successful in control and prevention of infectious diseases in both domestic and wild animals (Pearson et al., 2005).

General principles of animal disease control and eradication (Geering et al., 1999), constitutes several applied approaches including:

- $\quad$ Avoiding contact between infected and susceptible animals

- $\quad$ Removing infected and potentially infected animals

- Reducing the number of susceptible animals and, close management on the cross interaction of domestic animals and wildlife's

- $\quad$ Reducing access of vectors to susceptible animals

- Denial of access of the disease agent to susceptible host animals

- Planned vaccination supplemented by other disease control measures

- $\quad$ Provide an environment that prevents or restricts the growth of pathogens

- $\quad$ Systematic pasture rotation system to breaks the life cycle of pathogens by removing the host

- Sanitation and use of disinfectants chemicals that restrict the growth of pathogens

\section{CONCLUSION}

Animal disease outbreaks pose significant threats to livestock genetic resource diversity throughout the world. The livestock sector is impaired by epizootics both from point of economic impacts of the disease itself and the measures taken to mitigate the risk of disease. Severe 
infectious epizootics are a serious threat to animal biodiversity and result in the degradation of ecosystem functioning. Contagious diseases represent a significant burden that affects public health, global economies and the conservation of biodiversity. Many animal species are under the threat of some or multiple infectious agents to the extent of limiting reproducibility and dramatic dead-off that gradually leads to species endangerment and extinctions.

Diseases epizootics are usually concerning distress mainly due to the globalization of trade leading to increased mobility of pathogens including invasive diseases. Prevention, control and eradication of diseases of endemic, endangered and economically important animals are national concerns. The control of infectious diseases transmissible among domestic animals, wildlife and to the public requires the development of intact disease mitigation strategies. Movement control of infected or high-risk animals and specimens is one of the main ways in mitigating or reducing the spread of infectious diseases. In areas where the risk of specific infection is particularly high, quarantine enhances pre-movement testing that enables to alleviate the spread to the mass.

\section{RECOMMENDATIONS}

Based on the aforementioned points, the following recommendations are forwarded:

- Adequate disease monitoring, prevention and control strategies should applied for safeguarding genetic diversity, animal health and the public

- The animal health diagnostic centers should be expanded and reinforced to ensure capability for both routine and emergency diagnostic needs to alert diseases occurrence

- Policy should be developed and strongly implemented to restrict the introduction of domestic animals in to wildlife habitats.

- Regulations and measures should be taken sufficiently on the movement of animals and their products into the country

\section{ACKNOWLEDGEMENTS}

I would like to praise the Almighty GOD who explores me throughout my life, and enabled me to achieve all my activities. I would like to express my deep and sincere appreciation and thanks to all animal biodiversity colleagues, particularly domestic animal biodiversity case-team members, for their intellectual support in editing and commenting my work.

\section{List of abbreviations:}

AnGR : Animal genetic resource

$\mathrm{Bd} \quad$ : Batrachochytrium dendrobatidis

CDV : Canine distemper virus

EID : Emerging infectious diseases

FAO : Food and agriculture organization of the United Nations: HPAI

Highly : Pathogenic avian influenza

IUCN : International union for conservation of nature

OIE : World organization for animal health

\section{REFERENCES}

Abdo-Salem, S., G. Gerbier, P. Bonnet, M. Al-Qadasi and A. Tran et al., 2006. Descriptive and spatial epidemiology of rift valley fever outbreak in Yemen 2000-2001. Annal. N.Y. Acad. Sci., 1081: 240-242.

Alemayehu, K., 2013. Threats, attempts and opportunities of conserving indigenous animal genetic resources in Ethiopia. Afr. J. Agric. Res., 8: 2806-2813.

Alexander, K.A. and M.J. Appel, 1994. African wild dogs (Lycaon pictus) endangered by a canine distemper epizootic among domestic dogs near the Masai Mara National Reserve, Kenya. J. Wildl. Dis., 30: 481-485.

BOA., 1999. The Use of Drugs in Food Animals: Benefits and Risks. 1st Edn., National Academies Press, Washington, D.C., USA., ISBN: 9780309054348 , Page: 243.

Baillie, J., C. Hilton-Taylor and S.N. Stuart, 2004. 2004 IUCN Red List of Threatened Species: A Global Species Assessment. IUCN, USA., ISBN: 2-8317-0826-5, Pages: 191.

Bengis, R.G., R.A. Kock and J. Fischer, 2002. Infectious animal diseases: The wildlife/livestock interface. Rev. Sci. Tech., 21: 53-65.

Berger, L., R. Speare, P. Daszak, D.E. Green and A.A. Cunningham et al., 1998. Chytridiomycosis causes amphibian mortality associated with population declines in the rain forests of Australia and Central America. Proc. Natl. Acad. Sci. USA., 95: 9031-9036.

Bishop, S.C. and J.A. Woolliams, 2004. Genetic approaches and technologies for improving the sustainability of livestock production. J. Sci. Food Agric., 84: 911-919.

Bouley, T., M. Gilbert, P. Whung, F. Le Gall and C. Plante, 2014. Reducing climate-sensitive disease risks. Agriculture and Environmental Services Discussion Paper No 7, World Bank Group, Washington, D.C., USA. http://documents. worldbank.org/curated/en/486511468167944431/R educing-climate-sensitive-disease-risks 
Breed, A.C., R.K. Plowright, D.T. Hayman, D.L. Knobel and F.M. Molenaar et al., 2009. Disease Management in Endangered Mammals. In: Management of Disease in Wild Mammals, Delahay, R.J., G.C. Smith and M.R. Hutchings (Eds.). Springer, Tokyo, ISBN: 978-4-431-77133-3, pp: 215-239.

Carlton, J.T., G.J. Vermeij, D.R. Lindberg, D.A. Carlton and E.C. Dubley, 1991. The first historical extinction of a marine invertebrate in an ocean basin: The demise of the eelgrass limpet Lottia alveus. Biol. Bull., 180: 72-80.

Caron, A., E. Miguel, C. Gomo, P. Makaya and D.M. Pfukenyi et al., 2013. Relationship between burden of infection in ungulate populations and wildlife/livestock interfaces. Epidemiol. Infect., 141: 1522-1535.

Clegg, S.B., P.C.B., C.M. Foggin and P.M. Lindeque, 2007. Massive outbreak of anthrax in wildlife in the Malilangwe wildlife reserve, Zimbabwe. Vet. Rec., 160: 113-118.

Cunningham, A.A. and P. Daszak, 1998. Extinction of a species of land snail due to infection with a microsporidian parasite. Conserv. Biol., 12: 1139-1141.

Daszak, P., A. Strieby, A.A. Cunningham, J.E. Longcore, C.C. Brown and D. Porter, 2004. Experimental evidence that the bullfrog (Rana catesbeiana) is a potential carrier of chytridiomycosis, an emerging fungal disease of amphibians. Herpetological J., 14: 201-207.

Daszak, P., A.A. Cunningham and A.D. Hyatt, 2000. Emerging infectious diseases of wildlife-Threats to biodiversity and human health. Science, 287: 443-449.

De Castro, F. and B. Bolker, 2005. Mechanisms of disease-induced extinction. Ecol. Lett., 8: 117-126.

DeLiberto, T. and G. Keirn, 2016. Tracking a deadly virus highly pathogenic avian influenza in wild birds. Wildl. Prof., 10: 34-37.

Diaz, G.J., 2011. Toxic plants of veterinary and agricultural interest in Colombia. Int. J. Poisonous Plant. Res., 1: 1-19.

Engdawork, A., 2019. Review: Milk fever and its economical impacts in commercial dairy cattle production. Int. J. Agric. Agribusiness, 2: 221-242.

FAO., 2004. Control and eradication of highly pathogenic avian influenza in Asia. Food and Agriculture Origanization, Rome, Italy.

FAO,, 2007. The State of the World's Animal genetic Resources for Food and Agriculture. Commision on Genetic Resources Food and Agriculture, Rome, Italy.

FAO,, 2009. The state of the food and agriculture: Livestock in the balance. Food and Agriculture Organization of the United Nations, Rome, Italy.
FAO., 2010. Status and trends report on animal genetic resources. Food and Agriculture Organization of the United Nations, Rome, Italy.

FAO., 2012. Agricultural mechanization: Rural infrastructure and agroindustries. Food and Agriculture Organization, Rome, Italy.

Fisher, M.C., T.W. Garner and S.F. Walker, 2009. Global emergence of Batrachochytrium dendrobatidis and amphibian chytridiomycosis in space, time and host. Annu. Rev. Microbiol., 63: 291-310.

Frick, W.F., J.F. Pollock, A.C. Hicks, K.E. Langwig and D.S. Reynolds et al., 2010. An emerging disease causes regional population collapse of a common North American bat species. Science, 329: 679-682.

Geering, W.A., P.L. Roeder, T.U. Obi and M.M. Rweyemamu, 1999. Manual on the Preparation of National Animal Disease Emergency Preparedness Plans. Vol. 6, Food and Agriculture Organization, Rome, Italy, ISBN: 9789251042908, Pages: 83.

Getachew, A., 2005. Review article trypanosomosis in Ethiopia. Acad. J. Anim. Dis., 1: 11-15.

Gibson, J., S. Gamage, O. Hanotte, L. Iniguez and J.C. Maillard et al., 2006. Options and strategies for the conservation of farm ani-mal genetic resources. Master Thesis, AGROPOLIS, Montpellier, France.

Givens, D., 2010. Milk and meat in our diet, human nutrition and health for poverty reduction in developing countries. J. Anim. Sci., 85: 2788-2800.

Gordon, C.H., A.C. Banyard, A. Hussein, M.K. Laurenson and J.R. Malcolm et al., 2015. Canine distemper in endangered Ethiopian wolves. Emerging Infect. Dis., 21: 824-832.

Gortazar, C., P. Acevedo, F. Ruiz-Fons and J. Vicente, 2006. Disease risks and overabundance of game species. Eur. J. Wildl. Res., 52: 81-87.

Hanger, J.J., L.D. Bromham, J.J. McKee, T.M. O'Brien and W.F. Robinson, 2000. The nucleotide sequence of koala (Phascolarctos cinereus) retrovirus: A novel type $\mathrm{c}$ endogenous virus related to gibbon ape leukemia virus. J. Virol., 74: 4264-4272.

Harder, T.C., M. Kenter, H. Vos, K. Siebelink and W. Huisman et al., 1996. Canine distemper virus from diseased large felids: Biological properties and phylogenetic relationships. J. Gen. Virol., 77: 397-405.

Hochachka, W.M. and A.A. Dhondt, 2000. Density-dependent decline of host abundance resulting from a new infectious disease. Proc. Nat. Acad. Sci., 97: 5303-5306.

Hubalek, Z. and I. Rudolf, 2010. Types of Human Disease by Source of the Infectious Agent. In: Microbial Zoonoses and Sapronoses, Hubalek, Z. and I. Rudolf (Eds.). Springer, Berlin, Germany, ISBN: 978-90-481-9656-2, pp: 5-8. 
Hugh-Jones, M.E. and V. de Vos, 2002. Anthrax and wildlife. Rev. Scientifique Tech. Office Int. Epizooties, 21: 359-384.

Jones, K.E., N.G. Patel, M.A. Levy, A. Storeygard and D. Balk et al., 2008. Global trends in emerging infectious diseases. Nature, 451: 990-993.

Joshi, S.K. and G. Jadon, 2012. Introduction to neoplasm: Tumor classification a review article. Int. J. Adv. Res. Pharm. Biosci., 1: 227-263.

Kahn, C.M. and S. Line, 2010. Breast Blisters: The Merck Veterinary Manual. 10th Edn., Merck and Co. Inc., New Jersey, USA.

Kuzmin, I.V., L.A. Orciari, Y.T. Arai, J.S. Smith, C.A. Hanlon, Y. Kameoka and C.E. Rupprecht, 2003. Bat lyssaviruses (Aravan and Khujand) from central Asia: Phylogenetic relationships according to N, P and $\mathrm{G}$ gene sequences. Virus Res., 97: 65-79.

Laurance, W.F., K.R. McDonald and R. Speare, 1996. Epidemic disease and the catastrophic decline of Australian rain forest frogs. Conserv. Biol., 10: 406-413.

Laurenson, M.K., C. Sillero-Zubiri, H. Thompson, F. Shiferaw and J.R. Malcolm, 1998. Disease threats to endangered species: Patterns of infection by canine pathogens in Ethiopian wolves (Canis simensis) and sympatric domestic dogs. Anim. Conserv., 1: 273-280.

Lembo, T., K. Hampson, H. Auty, C.A. Beesley and P. Bessell et al., 2011. Serologic surveillance of anthrax in the Serengeti ecosystem, Tanzania, 1996-2009. Emerging Infect. Dis., 17: 387-394.

Lemma, H., 2012. Domestic animal biodiversity in Ethiopia and its threats and opportunities with emphasis to changing climate: An overview. Adv. Life Sci. Techol., 6: 33-39.

Leroy, E.M. and P. Telfer, B. Kumulungui, P. Yaba and P. Rouquet et al., 2004. A serological survey of Ebola virus infection in central African nonhuman primates. J. Infect. Dis., 190: 1895-1899.

Leslie, J. and M. Upton, 1999. The economic implications of greater global trade in livestock and livestock products. Rev. Sci. Tech. Off. Int. Epiz., 18: 440-457.

Longcore, J.E., A.P. Pessier and D.K. Nichols, 1999. Batrachochytrium dendrobatidis gen. et sp. nov., a chytrid pathogenic to amphibians. Mycologia, 91: 219-227.

MOA., 2012. Draft document on the establishment of disease-free zones. Ministry of Agriculture, Ethiopia.

MacPhee, R.D. and A.D. Greenwood, 2013. Infectious disease, endangerment and extinction. Intl. J. Evol. Biol., Vol. 2013,

MacPhee, R.D., 1997. The 40,000-year plague: Humans, hyperdisease, and first-contact extinctions. Nat. Change Hum. Impact Madagascar, 1: 169-217.
Mackey, T.K., B.A. Liang, R. Cuomo, R. Hafen, K.C. Brouwer and D.E. Lee, 2014. Emerging and reemerging neglected tropical diseases: a review of key characteristics, risk factors, and the policy and innovation environment. Clin. Microbiol. Rev., 27: 949-979.

Marino, J., 2003. Threatened Ethiopian wolves persist in small isolated Afroalpine enclaves. Oryx, 37: 62-71.

Modiano, J., 2016. Comparative pathogenesis of cancers in animals and humans. Vet. Sci., Vol. 3, No. 3.

Murchison, E.P., O.B. Schulz-Trieglaff, Z. Ning, L.B. Alexandrov and M.J. Bauer et al., 2012. Genome sequencing and analysis of the Tasmanian devil and its transmissible cancer. Cell, 148: 780-791.

Murphy, S.P. and L.H. Allen, 2003. Nutritional importance of animal source foods. J. Nutr., 133: 3932S-3935S.

OIE., 2005. OIE situation report for avian influenza in animals (types H5 and H7). OIE-World Organisation for Animal Health, Paris, France.

OIE., 2014. OIE guidelines for the control of animal disease. OIE-World Organisation for Animal Health, Paris, France.

Orth, R.J., T.J.B. Carruthers, W.C. Dennison, C.M. Duarte and J.W. Fourqurean et al., 2006. A global crisis for seagrass ecosystems. BioScience, 56: 987-996.

Pankhurst, R., 1985. The History of Famine and Epidemics in Ethiopia Prior to Twentieth Century. Relief and Rehabilitation Commission, Addis Ababa, Ethiopia, Pages: 120.

Pearse, A.M. and K. Swift, 2006. Allograft theory: Transmission of devil facial-tumour disease. Nature, Vol. 439,

Pedersen, A.B., K.E. Jones, C.L. Nunn and S.A. Altizer, 2007. Infectious disease and mammalian extinction risk. Conserv. Biol., 21: 1269-1279.

Perry, B., T.F. Randolph, J.J. McDermont, K.R. Sones and P.K. Thornton, 2002. Investing in Animal Health Research to Alleviate Poverty. International Livestock Research Institute (ILRI), Nairobi, Kenya, ISBN-13: 9789291461080, Pages: 140.

Phoofolo, P., 1993. Epidemics and revolutions: The rinderpest epidemic in late nineteenth-century Southern Africa. Past Present, 1: 112-143.

Pounds, J.A., M.P. Fogden, J.M. Savage and G.C. Gorman, 1997. Tests of null models for Amphibian declines on a tropical mountain. Conserv. Biol., 11: 1307-1322.

Rands, M.R.W., W.M. Adams, L. Bennun, S.H.M. Butchart and A. Clements et al., 2010. Biodiversity conservation: Challenges beyond 2010. Science, 329: 1298-1303. 
Roelke-Parker, M.E., L. Munson, C. Packer, R. Kock and S. Cleaveland et al., 1996. A canine distemper virus epidemic in Serengeti lions (Panthera leo). Nature, 379: 441-445.

Rouquet, P., J.M. Froment, M. Bermejo, A. Kilbourn and W. Karesh et al., 2005. Wild animal mortality monitoring and human Ebola outbreaks, Gabon and Republic of Congo, 2001-2003. Emerging Infect. Dis., 11: 283-290.

Rushton, J., R. Viscarra, E.G. Bleich and A. McLeod, 2004. Impact of avian influenza outbreaks in the poultry sectors of five South East Asian countries (Cambodia, Indonesia, Lao PDR, Thailand, Vietnam) outbreak costs, responses and potential long term control. FAO, Rome, Italy, pp: 1-25. http://www.fao.org/docs/eims/upload/214194/rusht on-comp.pdf.

Schloegel, L.M., A.M. Picco, A.M. Kilpatrick, A.J. Davies, A.D. Hyatt and P. Daszak, 2009. Magnitude of the US trade in amphibians and presence of Batrachochytrium dendrobatidis and ranavirus infection in imported North American bullfrogs (Rana catesbeiana). Biol. Conserv., 142: 1420-1426.

Scott, G.R., 2000. The Murrain now known as rinderpest. Newsletter Trop. Agric. Assoc. UK., 20: 14-16.

Shiferaw, F., S. Abditcho, A. Gopilo and M.K. Laurenson, 2002. Anthrax outbreak in Mago National Park, Southern Ethiopia. Vet. Record, 150: 18-20.

Skerratt, L.F., L. Berger, R. Speare, S. Cashins and K.R. McDonald et al., 2007. Spread of chytridiomycosis has caused the rapid global decline and extinction of frogs. EcoHealth, 4: 125-134.

Smith, K.F., D.F. Sax and K.D. Lafferty, 2006. Evidence for the role of infectious disease in species extinction and endangerment. Conserv. Biol., 20: 1349-1357.

Smith, K.F., M. Behrens, L.M. Schloegel, N. Marano, S. Burgiel and P. Daszak, 2009. Reducing the risks of the wildlife trade. Science, 324: 594-595.

Sordillo, L.M. and W. Raphael, 2013. Significance of metabolic stress, lipid mobilization and inflammation on transition cow disorders. Vet. Clin. Food Anim. Pract., 29: 267-278.
Springbett, A.J., K. MacKenzie, J.A. Woolliams and S.C. Bishop, 2003. The contribution of genetic diversity to the spread of infectious diseases in livestock populations. Genetics, 165: 1465-1474.

Stark, K.D.C. and M.D. Salman, 2001. Relationships between animal health monitoring and the risk assessment process. Acta Vet. Scand. Suppl., 42: S71-S77.

Tarlinton, R., J. Meers, J. Hanger and P. Young, 2005. Real-time reverse transcriptase PCR for the endogenous koala retrovirus reveals an association between plasma viral load and neoplastic disease in koalas. J. Gen. Virol., 86: 783-787.

Tilman, D., J. Fargione, B. Wolff, C. D'Antonio and A. Dobson et al., 2001. Forecasting agriculturally driven global environmental change. Science, 292: 281-284.

Turton, J., 2000. Causes of disease in animals. National Department of Agriculture in cooperation with the ARC, Onderstepoort Veterinary Institute, South $\begin{array}{lllllll}\text { A } & f & \mathrm{r} & \mathrm{i} & \mathrm{c} & \mathrm{a}\end{array}$ https:/www.nda.agric.za/docs/Infopaks/diseases.htm

Van de Bildt, M.W.G., T. Kuiken, A.M. Visee, S. Lema, A.R. Fitzjohn and A.D.M.E. Osterhaus, 2002. Distemper outbreak and its effect on African wild dog conservation. Emerg. Infect. Dis., 8: 211-213.

Warner, R.E., 1968. The role of introduced diseases in the extinction of the endemic Hawaiian avifauna. Condor, 70: 101-120.

Weingartl, H.M., C. Embury-Hyatt, C. Nfon, A. Leung, G. Smith and G. Kobinger, 2012. Transmission of Ebola virus from pigs to non-human primates. Sci. Rep., Vol. 2, 10.1038/srep00811

Williams, E.S., E.T. Thome, M.J. Appel and D.W. Belitsky, 1988. Canine distemper in black-footed ferrets (Mustela nigripes) from Wyoming. J. Wildl. Dis., 24: 385-398.

Zewde, B., 2002. A History of Modern Ethiopia: 1855-1991. 2nd Edn., Ohio University Press, Ohio, ISBN: 0821414402, Pages: 300. 